\title{
The Complete Nucleotide Sequences of L3 and S7 Segments of Ibaraki Virus Encoding for the Major Inner Capsid Proteins, VP3 and VP7
}

\author{
Hiroyuki IWATA ${ }^{1)}$, Sachiho MANABE ${ }^{1)}$, Ayumi YOSHIDA $^{1)}$, Eva Megumi Nara PEREIRA ${ }^{1)}$ and Takeshi INOUE ${ }^{1)}$ \\ ${ }^{1)}$ Department of Veterinary Hygiene, Faculty of Agriculture, Yamaguchi University, 1677-1 Yoshida, Yamaguchi, Yamaguchi 753-8515, \\ Japan
}

(Received 19 July 2000/Accepted 26 September 2000)

ABSTRACT. The complete nucleotide sequences of the genes encoding two of the major inner capsid proteins of Ibaraki virus (IBAV), belonging to epizootic hemorrhagic disease virus serotype 2 (EHDV-2) were determined. The L3 RNA segment is 2768 nucleotides in length which encodes VP3 polypeptides of 899 amino acid residues (M.W. $103 \mathrm{kDa}$ ). The S7 RNA segment, which encodes the VP7 core protein, is 1162 nucleotides in length and encodes 349 amino acids (M.W. $38 \mathrm{kDa}$ ). These RNA segments had the characteristic consensus motifs of Orbivirus RNA segments in termini, namely 5'-GUUAAA... and ...ACUUAC-3'. The comparison of the IBAV L3 and S7 sequences with those of other two EHDV-2 isolates revealed the higher homologies of $93 \%$ and $92 \%$ against EHDV-2 Australia isolate (EHDV-2AUS) and lower homologies of $80 \%$ and $81 \%$ against EHDV-2 North America isolate, respectively. The phylogenetic analysis based on L3 and S7 genes also indicated close relationships between IBAV and EHDV-2AUS.

KEY WORDS: dsRNA gene, Ibaraki virus, inner capsid, VP3, VP7.

J. Vet. Med. Sci. 63(1): 73-78, 2001

Ibaraki virus (IBAV) is a strain of epizootic hemorrhagic disease virus serotype 2 (EHDV-2) belonging to the genus Orbivirus in the family Reoviridae [18, 19]. The virus is composed of seven structural proteins organized in a doublelayered capsid containing the 10 dsRNA segments (L1-3, M4-6, S7-10) of the viral genome [22]. The inner capsid is composed of two major proteins, VP3 and VP7, and three minor structural proteins (VP1, 4 and 6). The segment L3 of viral genes encodes the inner capsid protein of VP3 which constitute the viral subcore [5]. This subcore is surrounded by 260 trimers of VP7 encoded by segment S7 to form the core particles, which has a knobby surface appearance in an icosahedral symmetry [13]. The inner capsid proteins were considered to be serogroup-specific and associated with infectivity to insect [9]. Previous phylogenetic analyses based on bluetongue virus (BTV) gene segment L3 indicated a geographical distribution of different genotypes, while the BTV S7 nucleotide sequences did not unequivocally display geographic distribution as seen in L3 [24]. The Nucleotide sequences of EHDV-2 L3 and S7 segments have been reported on the Australia (EHDV-2AUS) and North America isolates (EHDV-2NA) [2, 4, 10, 24]. The identity of L3 sequence between these two EHDV-2 subtypes was about $80 \%$, but EHDV-2NA had a higher homology to EHDV-1 than that to EHDV-2AUS. Although partial nucleotide sequence of IBAV L3 segment has also been reported [4], the sequences of S7 and full-length L3 genes are still unknown. We previously described the nucleotide sequences of L2 and M5 genes encoding the major outer capsid proteins of VP2 and VP5 on IBAV $[11,12]$. There are some genetic differences of L2 genes between Japan and North America isolates of EHDV-2 (70\% nucleotide identity) in spite of the same serotype. Since L2 and/or M5 sequence for North America and Australia isolates has not been analysed, the genetic relationships among three EHDV-2 isolates have not been estab- lished. In this study, the complete nucleotide sequences of viral gene segment L3 and S7 of IBAV were analysed in order to investigate genetic relationships among EHDV-2 isolates with regard to the genes encoding inner capsid proteins.

\section{MATERIALS AND METHODS}

Viruses, cells and isolation of dsRNA: Ibaraki virus No.2 strain, which was kindly given from National Institute of Animal Health, Japan, was plaque-purified and propagated using monolayers of HmLu-1 cells in minimal essential medium (MEM; Nissui Pharmaceutical Corp., Ltd, Japan) supplemented with 5\% fetal calf serum (FCS; M.A. Bioproducts, Inc., U.S.A.). The viral dsRNAs were purified from HmLu-1 cells infected with IBAV and the segment L3 and S7 RNAs of IBAV were separated on agarose gel electrophoresis and recovered as described elsewhere [14].

Synthesis of cDNA: The L3 and S7 dsRNA was transcribed into cDNA by the Marathon ${ }^{\mathrm{TM}}$ cDNA amplification kit (Clontech Laboratories, Inc., U.S.A.) using a random primer according to the manufacturer's instruction. The cDNA blunt-ended with T4 DNA polymerase was ligated to the Marathon cDNA adaptor and was amplified by the polymerase chain reaction (PCR) method using adaptor primer or L3 specific primers designed from the sequence data of EHDV-2AUS (CSIRO439) and EHDV-2NA (sv 124) to obtain cDNA containing the whole ORF as follows; EHD2L3F: 5'-GTT AAA TTT CCA GAG CGA TG-3' (as a sense primer) and EHD2L3R: 5'-GCA AAT ATT AGT AGC AGA TAT CTA-3' (as an antisense primer). PCR conditions were 30 cycles of amplification with a denaturation temperature of $94^{\circ} \mathrm{C}$ for $1 \mathrm{~min}$, an annealing temperature of $50^{\circ} \mathrm{C}$ for $1 \mathrm{~min}$, and an extension temperature of $72^{\circ} \mathrm{C}$ for 3 min. The cDNA fragments were cloned into pMosBlueT 
vector (Amersham Life Science, Inc., U.K.) or pGEM ${ }^{\circledR}-$ T Easy vector (Promega Corp., U.S.A.) by TA cloning procedure and introduced into Escherichia coli (E. coli) XL-1 Blue. The clones were randomly selected and screened by Hinf I restriction pattern and sequence analyses of both termini of the insert.

5'- and 3'-terminal cDNA clones: To determine both terminal sequences, the terminal cDNAs were synthesized from purified L3 and S7 dsRNAs by 5'-rapid amplification of cDNA (RACE) method using 5'-Full RACE core set (TaKaRa, Japan) according to the manufacturer's instruction. In brief, 5'-terminal phosphorylated primers were designed from the sequence data of cDNA obtained by the above method, which produced a single stranded (ss) cDNA of about 500 base from 5' or 3' terminus. After hybridization of the 5'-terminal phosphorylated primer to single stranded (ss) RNA, cDNA was extended to the 5'-terminus by reverse transciptase and was digested with RNase H. Resulted ss cDNA was circularized or concatemerized using T4 RNA ligase and amplified by PCR method using TaKaRa Ex $\mathrm{Taq}^{\mathrm{TM}}$ (TaKaRa). The PCR product was cloned into pGEM $^{\circledR}$-T Easy vector by TA cloning procedure and transformed into $E$. coli.

Sequencing of cDNA clones: Appropriate cDNA fragments were subcloned into pUC118 and deletion derivatives were generated following the ExoIII/Mung Bean Nuclease Deletion Kit protocol (Stratagene, U.S.A.). The sequences of both strands were determined by the cycle sequenceing protocols using ABI Prism BigDye ${ }^{\mathrm{TM}}$ terminator cycle sequencing ready reaction kit (The Perkin-Elmer Corp., U.S.A.). The sequence analysis was carried out using ABI Prism 377 autosequencer. To confirm sequence data, at least two overlapped or PCR-derived clones were analysed. Sequence alignment and phylogenetic analysis were performed by a CLUSTALW program (DNA Data bank of Japan, National Institute of Genetics, Japan) [ 21 ].

\section{RESULTS}

Complete nucleotide sequence of L3 cDNA: The fulllength cDNA of L3 segment was 2768 nucleotides in length (DDBJ/EMBL/GenBank Accession Number: AB041933) and the coding strand had a calculated base composition of $30.7 \%$ A, $17.8 \%$ C, $24.4 \%$ G, and $27.1 \%$ T. The characteristic conserved terminal hexanucleotides commonly found in Orbvirus genes, namely 5'-GTTAAA... and ...ACTTAC-3', were present (Fig. 1). An open reading frame (ORF) of 2697 nucleotides, beginning with an ATG at position 18 to 20 and terminating at position 2698 to 2700 with a TAA codon, was flanked by 5' non-coding region of 17 base pairs (bp) and 3' non-coding region of $54 \mathrm{bp}$. The translated ORF generated a deduced amino acid sequence of 899 residues with a calculated molecular weight (M.W.) of 102,917 Da which contained 465 residues of hydrophobic amino acids (51.7\%).

Comparison of L3 gene and VP3 protein among Orbiviruses: Comparison of L3 gene and VP3 protein sequences among Orbiviruses were performed by a CLUSTALW program [21]. Sequence analyses of IBAV L3 gene showed high identities of $93 \%$ with EHDV-2AUS, $80 \%$ with EHDV2NA and EHDV-1 [8], while percent identities against BTV10 and African horse sickness virus serotype 4 (AHSV-4) [6] were $63 \%$ and $53 \%$, respectively. The alignment of VP3

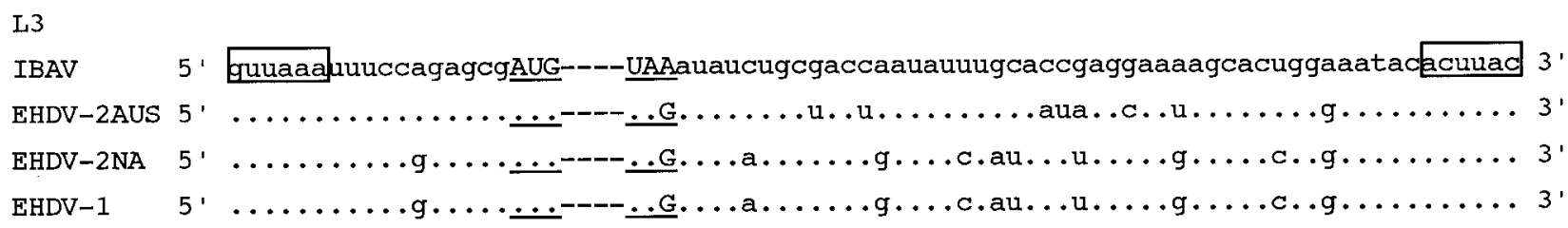

S7

IBAV 5' EuuaaakuuggugaaaAUG---UGAgggcuguuauggcacggcauaacgcucacauacgcccgugucauugucuggau

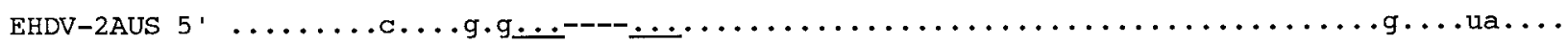

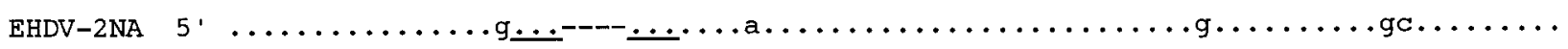

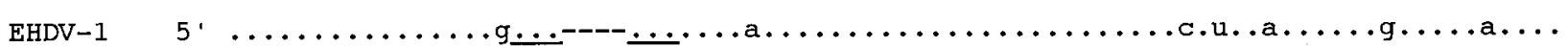

\begin{tabular}{|c|c|}
\hline IBAV & aacgggucauccauuugcacguuuucccaaauuca acuuad \\
\hline EHDV-2AUS &.$g$. u.c......cc..g...c...u..... \\
\hline EHDV-2NA & $\cdots, \ldots \ldots \ldots \ldots \ldots \ldots \ldots \ldots \ldots$ \\
\hline EHDV-1 & $\cdot \mathrm{u}$. \\
\hline
\end{tabular}

Fig. 1. Comparison of the 5' and 3' non-coding region of S7 and L3 segments of Ibaraki virus(IBAV) with those of other EHDVs. The characteristic consensus motifs of Orbivirus RNA segments in termini are boxed. Start and stop codons are underlined. 
IBAV EHDV-2AUS EHDV-2NA EHDV-1

IBAV EHDV-2AUS EHDV-2NA EHDV-1

IBAV EHDV-2AUS EHDV-2NA EHDV-1

IBAV EHDV-2AUS EHDV-2NA EHDV-1

IBAV EHDV-2AUS EHDV-2NA EHDV-1

IBAV EHDV-2AUS EHDV-2NA EHDV-1

IBAV EHDV-2AUS EHDV-2NA EHDV-1

IBAV EHDV-2AUS EHDV-2NA EHDV-1

IBAV EHDV-2AUS EHDV-2NA EHDV-1

IBAV EHDV-2AUS EHDV-2NA EHDV-1

IBAV EHDV-2AUS EHDV-2NA EHDV-1

IBAV EHDV-2AUS EHDV-2NA EHDV-1
1 MAEPPDAATPKTSPYLKGDELSSDSGPLLSIFALQEIMQKVRQAQSEYVAATKDVDLTIPDVQKIIDGVKELASE

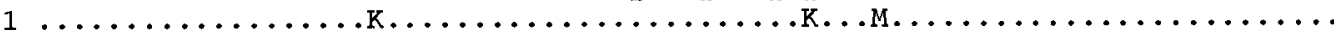

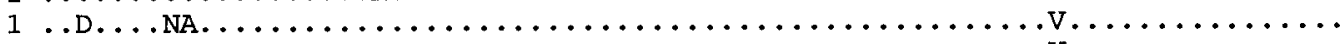

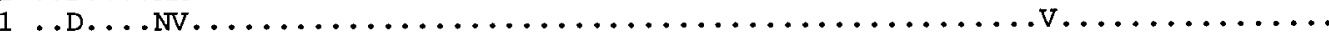

76 TIYKVVNKPLISYRHIVMQSRDRFLRVDTYYERMSEVGDKIDENEPAKFYETVIKKVRHLRTEGAFVLHNIPTRD 76

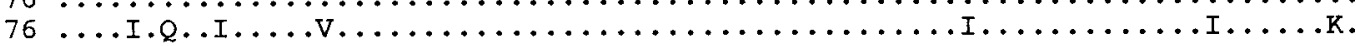

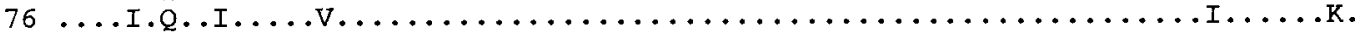

151 HRGMEIADPEILGVDVKSILPVLTAEHRAMVQHILDGAIIENGNVATRDVDVYLGACSESVYRIYNRLQGYVEAV

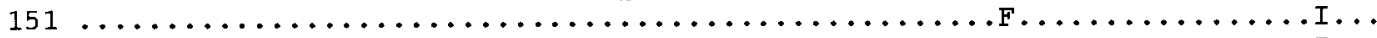

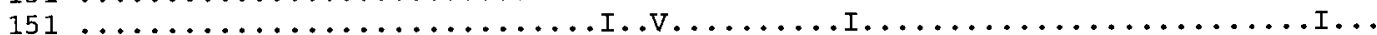

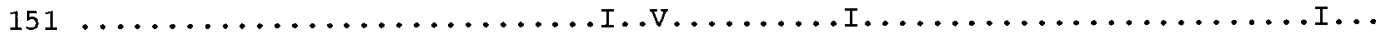

226 QLEELRAAITWLERIGRRKRMTFSQEFLTDFRRADTIWVLALQLPANPRVIWDVPRCSIANLIMNIATCLPTGEY 226

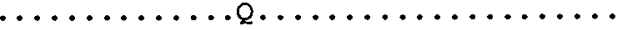

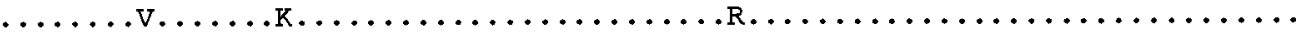

301 VSPNPRIASITLTQRITTTGPFAILTGSTPTAQQLDDVRKIYLALMFPGQIILDLKIDPGERMDPAVSMVAGVVG

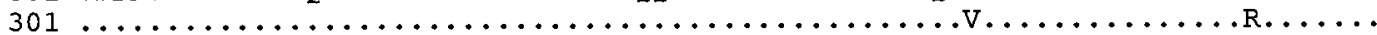

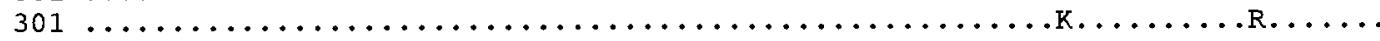

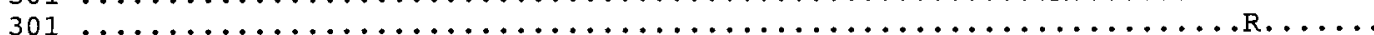

376 HLMFTAGPRFTNITQNMARQLDIALADFLLYMYNTRIQVQYGPTGEPLDFRIGRGQYDCNAFRTNFQTGAGYNGW 376

376

376

451 GLVDVENREPAPYDHVQRF IRYCNIDSRELIHPATFGIGMNYYCYNERT RYLVAAGKDTEAAF FRNVLPFHMVRF

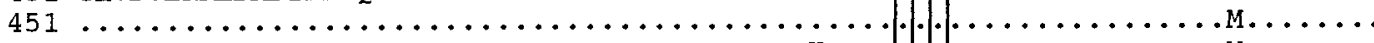

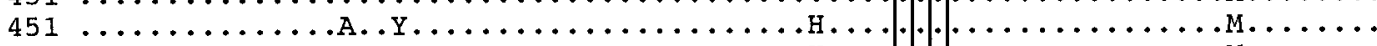

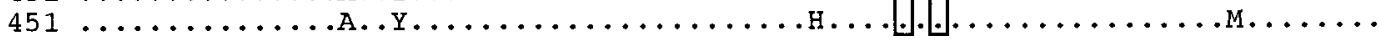

526 ARINQIINEDLHSAFSMPDDQFNVLLANMIAGAQERMDPVVLDISWISIWYAFNRSFEPTRRNEMLESAPLIESV

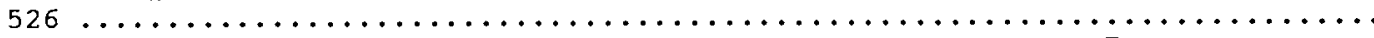

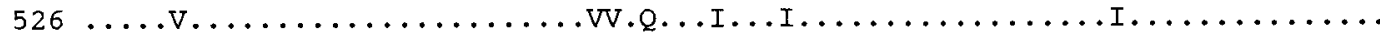

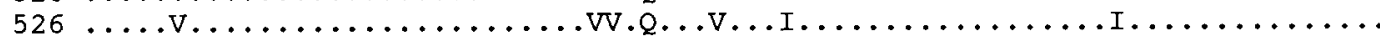

601 YASELTVMKTDMQQMALLQRRFPDVLVEARPTHFWKAVMEVSPEPVRAIMDLAHSHSF INIRDMMRWIGLPSMQN

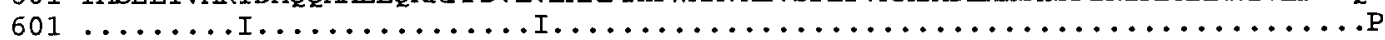

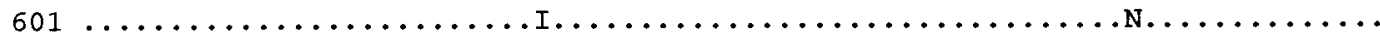

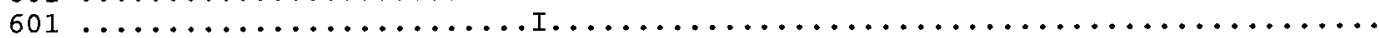

676 SMKLVLEEEAWAVANDFEELMLTDQVYMFRDMLPEPRLDDIERFRQEGFYYTNMLDGPPAIDRVVQYTYEVARIQ

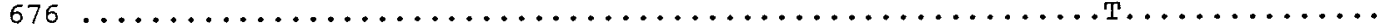

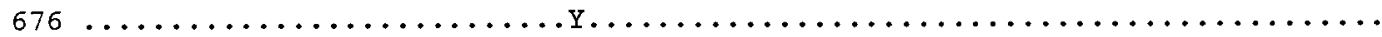

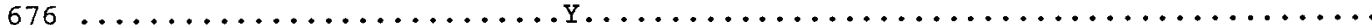

751 ANMGQLRAALRRIMDDEGWVRFGGVLRTVRVKFFDSRPPEEILQALPFDYQTSEKGGLTYATIKYANDTTIYYLI

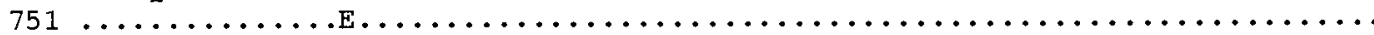

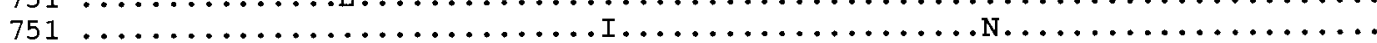

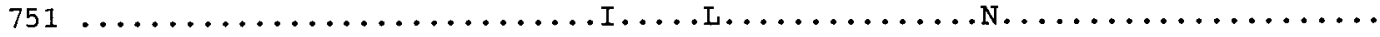

826 YNVEYSNLPDSLVLINPTYVMTKVF INKRIVERVRVGQALAVMNKRF IAYKGKMRIMDITQALKVGTKLAAPTV826

Fig. 2. Alignment of the deduced amino acid sequence of the Ibaraki virus (IBAV) VP3 protein with those of EHDV-2AUS (CSIRO439), EHDV-2NA (sv 124) and EHDV-1. Essential residues for CLPs formation are boxed. Dots indicate identical amino acids to IBAV sequence and a hyphen indicates a gap.

amino acid sequence of IBAV with those of EHDV-2AUS, EHDV-2NA and EHDV-1 are shown in Fig. 2. The homologies of the deduced amino acids were $98 \%$ to EHDV-2AUS and $95 \%$ to EHDV-2NA and EHDV-1, whereas EHDV-2NA
L3 gene had extremely high genotypic and phenotypic homologies of $98 \%$ and $99 \%$ to EHDV-1, respectively. The phylogenetic tree of the L3 sequence revealed that the AHSV, BTV and EHDV groups were very distinct (Fig. 4A). 


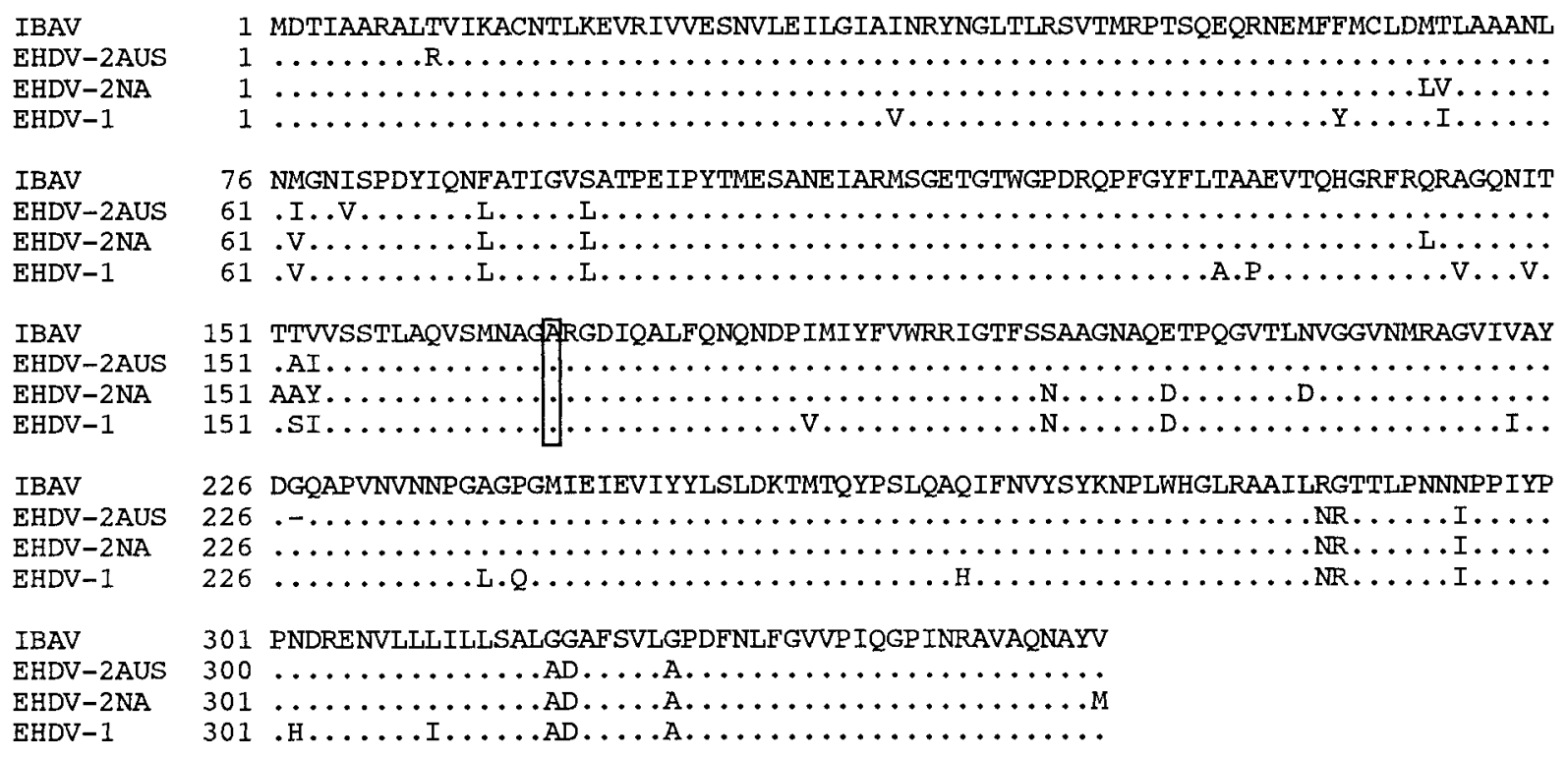

Fig. 3. Alignment of the deduced amino acid sequence of the Ibaraki virus (IBAV) VP7 protein with those of EHDV-2AUS (CSIRO439), EHDV-2NA (sv124) and EHDV-1. Alanine residue essential for the insoluble character at position 167 is boxed. Dots indicate identical amino acids to IBAV sequence and a hyphen indicates a gap.

In spite of the very low level of variability between the L3 sequences, it was evident from this analysis that EHDV-2NA and EHDV-1 sequences were unequivocally placed as a sister group, while IBAV showed closer relationship with EHDV-2AUS than EHDV-2NA. In addition, genetic relationships between IBAV and EHDV-2NA were more distant than those among BTV serotypes investigated to date.

Complete nucleotide sequence of S7 cDNA: The fulllength cDNA of S7 segment was 1162 nucleotides in length and the coding strand had a base composition of $30.6 \% \mathrm{~A}$, $19.7 \% \mathrm{C}, 24.3 \% \mathrm{G}$, and 25.4\% T (DDBJ/EMBL/GenBank Accession Number: AB041934), which was similar to other Orbivirus data and also to IBAV L3 gene. The conserved terminal hexanucleotides were also present as seen in the L3 sequence (Fig. 1). An ORF of 1,047 nucleotides, beginning with an ATG at position 18 to 20 and terminating at position 1,065 to 1,067 with a TGA codon, was flanked by 5' and 3' non-coding region of 17 and $95 \mathrm{bp}$, respectively. The ORF was 3 nucleotides longer than that of EHDV-2AUS and the same length as those EHDV-2NA and EHDV-1 [8]. The translated ORF generated a deduced amino acid sequence of 349 residues with a calculated M.W. of 37,999 Da containing 194 residues of hydrophobic amino acids (55.4\%).

Comparison of 57 gene and VP7 protein among Orbiviruses: The genotypic and phenotypic identities of S7 gene were also analysed as described above. The percent identities of S7 nucleotide sequence of IBAV against those of EHDV-2AUS, EHDV-2NA and EHDV-1were 92\%, 81\% and $79 \%$, respectively, while the percent identities against BTV-10 and AHSV-4 [16] were $63 \%$ and 57\%, respectively. The alignment of VP7 amino acid sequence of IBAV with those of EHDV-2AUS, EHDV-2NA and EHDV-1 are shown in Fig. 3. The identities of the deduced amino acids were
(A)

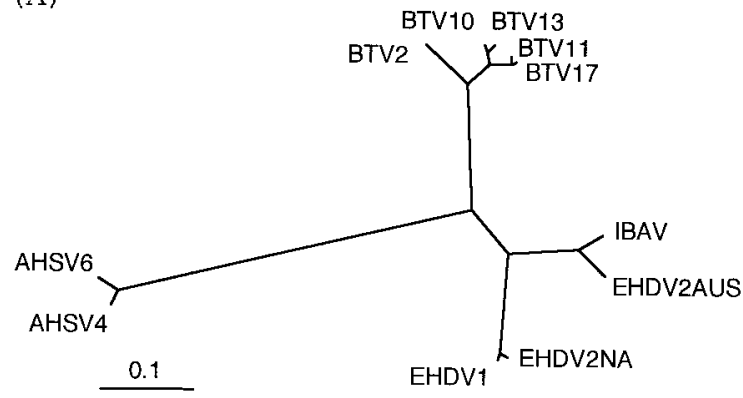

(B)

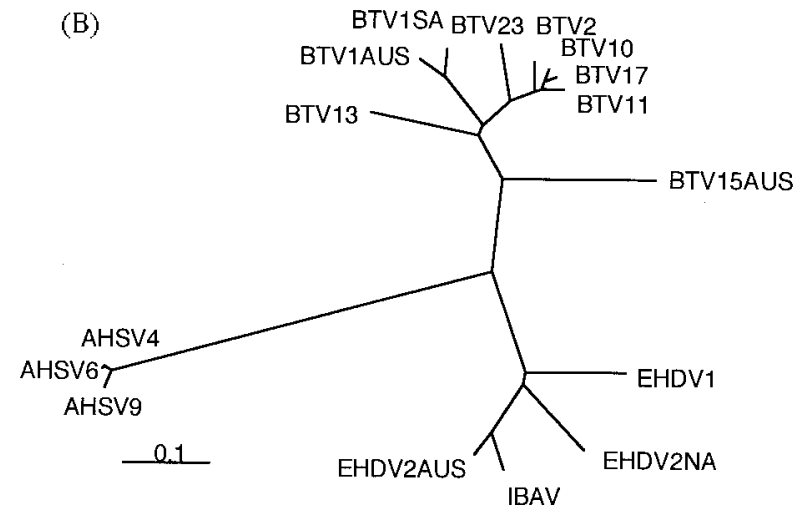

Fig. 4. Phylogenetic relationships of Ibaraki virus (IBAV) based on L3 (A) and S7 (B) sequences from different EHDV, BTV, and AHSV serotypes. Branch lengths are proportional to genetic distance calculated by the CLUSTAL W program. This figure is of a bootstrap analysis where this species order was predicted with $100 \%$ confidence at each node. 
$95 \%$ to EHDV-2AUS, $94 \%$ to EHDV-2NA and $92 \%$ to EHDV-1. Phylogenetically, the relationships between the S7 sequences of the AHSV, BTV and EHDV serogroups are shown in Fig. 4B. It is apparent from the profile that the serogroups are maintained as monophylectic clusters with the EHDV branch clearly more closely related to BTV than to AHSV. Although IBAV showed closer relationship to EHDV-2AUS than that to EHDV-2NA as seen in the L3 analysis, genetic distances of EHDV-2 isolates from EHDV1 were similar.

\section{DISCUSSION}

Epizootic hemorrhagic disease virus serotype 2 were isolated in Australia, North America and Japan. Although these isolates are expected to be closely related each other based on at least viral neutralization and hemagglutination test, genetic relationships are still unknown. We have previously described the viral genome sequences of outer capsid proteins, VP2 and VP5, of IBAV, which are the most variable proteins among Orbiviruses and have suggested that L2 has some extent of genetic distance between IBAV and North America isolates of EHDV-2 [11, 12]. However, L2 sequence of Australia isolate and M5 of Australia and North America isolates are not available for investigation of genetic relationship among these EHDV-2 isolates. In this study, we determined L3 and S7 sequence encoding for inner capsid proteins of VP3 and VP7, which were reported on Australia and North America isolates of EHDV-2 and genetic relationships among these three subtypes.

The 5' and 3' terminal sequences of L3 and S7 segments were found to contain the characteristic consensus sequences of Orbivirus RNA segments as seen in L2 and M5 genes [11, 12], which were considered to be important in transcription initiation, RNA replication, ribosome binding and translation of the mRNAs [15]. The deduced amino acid sequence of VP3 was 899 residues and had a low content of charged amino acids and a high content of hydrophobic amino acids similar to other Orbiviruses. In BTV, it was demonstrated that a methionine at residue 500 and an arginine at residue 502 were essential for CLP formation [20]. As expected from the low variability of VP3 amino acid sequences, the same structure was observed in IBAV. The VP7 amino acid sequence was 349 residues, which was one residue longer than EHDV-2AUS and the same as EHDV-2NA and EHDV1 , and also had a high hydrohobicity resulting in its highly insoluble nature. In VP7 sequence, the alanine residue at position 167 was reported to contribute to the insoluble character, which was also conserved in IBAV [1].

The comparison of four major capsid proteins among Orbiviruses indicated VP3 and VP7 were highly conserved and serogroup-specific, while the homologies of VP2 and VP5 between Orbiviruses were much lower, suggesting that VP2 and VP5 was serotype-specific [7]. These findings were also observed in the relationship between EHDV-1 and IBAV as well as other EHDV-2 isolates (data not shown). The comparison of L3 and S7 genes among three EHDV-2 isolates showed IBAV had a higher identity with EHDV2AUS than EHDV-2NA. Although the homology of L3 among BTV serotypes was more than $89 \%$, the homology between IBAV and EHDV-2NA was apparently lower $(80 \%)$ in spite of the same serotype. Phylogenetic analysis based on L3 and S7 sequences also showed that IBAV had closer relationship against EHDV-2AUS than EHDV-2NA and the genetic distance between IBAV and EHDV-2NA was similar to that between the BTV serotypes. In addition, EHDV-2NA showed apparently closer relationship against EHDV-1 than other EHDV-2 isolates as reported previously $[2,4]$, resulting in different branching on the phylogenetic tree compared to S7 analysis. Previous phylogenetic analyses based on Orbivirus gene segment L3 indicated a geographical distribution of different genotypes [4], but not S7 gene [24]. The different branching in EHDV-2 isolates might be also due to these geographical evolution and/or to reassortment between EHDVs as seen in BTV-1 South Africa and Australia isolates [3]. Furthermore, we previously described the distinction of L2 sequence between IBAV and EHDV-2NA and suggested sero-reactivity might not be consistent to genetic relationship. The findings obtained in this study has also speculated this point. The inner core proteins, especially VP7 which is important for insect cell attachment, were considered to be important for infectivity to insect cells and the insect vector species might affect the evolution of inner capsid proteins [2, 9, 24]. Similarly, EHDV might have evolved in the same fashion.

As mentioned above, the complete nucleotide sequences of segment L3 and S7 genes of IBAV was determined. IBAV showed close evolutionary relationships to Australia isolate of EHDV-2 and some genetic difference against EHDV-2NA by phylogenetic analyses based on L3 and S7 genes, suggesting Japan and Australia isolates of EHDV-2 might form a subgroup of an EHDV-2 serotype. In BTV, it was reported that subunit vaccine using CLPs and VLPs synthesized by co-expression of structure proteins protected sheep from BTV challenge [17]. In order to develop subunit vaccine of IBAV and to investigate its structure and function, the data in this study might contribute to further studies such as co-expressions of several virus proteins using recombinant techniques.

\section{REFERENCES}

1. Basak, A.K., Gouet, P., Grimes, R.P. and Stuart, D. 1996. Crystal structure of the top domain of African horse sickness virus VP7: comparison with bluetongue virus VP7. J. Virol. 70: 3797-3806.

2. Cheney, I.W., Larson, M.D., Mecham, J.O. and Wilson, W.C. 1995. Geographical genetic variation in the gene encoding VP3 from the Alberta isolate of epizootic hemorrhagic disease virus. Virus Res. 36: 279-286.

3. Cheney, I.W., Yamakawa, M., Roy, P., Mecham, J.O. and Wilson, W.C. 1996. Molecular characterization of the segment 2 gene of epizootic hemorrhagic disease virus serotype 2: gene sequence and genetic diversity. Virology 224: 555-560.

4. Gould, A.R. and Pritchard, L.I. 1991. Phylogenetic analyses of 
the complete nucleotide sequence of the capsid protein (VP3) of Australian epizootic haemorrhagic disease of deer virus (serotype 2) and cognate genes from other Orbiviruses. Virus Res. 21: 1-18.

5. Hewat, E.A., Booth, T.F. and Roy, P. 1992. Structure of bluetongue virus particles by cryo-electron microscopy. J. Struct. Biol. 109: 61-69.

6. Iwata, H., Chuma, T. and Roy, P. 1992. Characterization of the genes encoding two of the major capsid proteins of epizootic haemorrhagic disease virus indicates a close genetic relationship to bluetongue virus. J. Gen. Viol. 73: 915-924.

7. Iwata, H., Yamagawa, M. and Roy, P. 1992. Evolutionary relationships among the gnat-transmitted Orbivirus that cause African horse sickness, bluetongue, and epizootic hemorrhagic disease as evidenced by their capsid protein sequences. Virology 191: 251-261.

8. Le Blois, H., Fayard, B., Urakawa, T. and Roy, P. 1991. Synthesis and characterization of chimeric particles between epizootic hemorrhagic disease virus and bluetongue virus: Functional domains are conserved on the VP3 protein. J. Virol. 65: 48214831.

9. Mellor, P.S. 1990. The replication of bluetongue virus in Culicoides vectors. Curr. Top. Microbiol. Immunol. 162: 143-161.

10. Nagesha, H.S., Gould, A.R., White, J.R., Lunt, R.A. and Duch, C.J. 1996. Expression of the major inner capsid protein of the epizootic haemorrhagic disease virus in baculovirus and potential diagnostic use. Virus Res. 43: 163-169.

11. Pereira, E.M.N., Iwata, H. and Inoue, T. 2000. The complete nucleotide sequence of segment L2 of Ibaraki virus encoding for the antigen recognized by neutralizing antibody. J. Vet. Med. Sci. 62: 317-321.

12. Pereira, E.M.N., Nishida, T., Tokunaga, R., Iwata, H. and Inoue, T. 2000. Cloning and expression of the M5 RNA segment encoding outer capsid VP5 of epizootic hemorrhagic disease virus Japan serotype 2, Ibaraki virus. J. Vet. Med. Sci. 62: 301304.

13. Prasad, B.V.V., Yamaguchi, S. and Roy, P. 1992. Three-dimensional structure of single-shelled bluetongue virus. J. Virol. 66 :
2135-2142.

14. Purdy, M., Petre, J. and Roy, P. 1984. Cloning of the bluetongue virus L3 gene. J. Virol. 51: 754-759.

15. Rao, C.D., Kiuchi, A. and Roy, P. 1983. Homologous terminal sequences of the genome double-strand RNAs of bluetongue virus. J. Virol. 46: 378-383.

16. Roy, P., Hirasawa, T., Fernandez, M., Blinov, V.M. and Sanchez-Vixcain Rodrique, J.M. 1991. The complete sequence of the group-specific antigen, VP7, of African horsesickness disease virus serotype 4 reveals a close relationship to bluetongue virus. J. Gen. Virol. 72: 1237-1241.

17. Roy, P., Urakawa, T., Van Dijk, A.A. and Erasmus, B.J. 1990. Recombinant virus vaccine for bluetongue disease in sheep. $J$. Virol. 64: 1998-2003.

18. Suzuki, Y., Nakagawa, S., Namiki, M. and Saito, Y. 1978. RNA and protein of Ibaraki virus. Kitasato Arch. Exp. Med. 51: 61-71.

19. Suzuki, Y., Saito, Y. and Nakagawa, S. 1977. Double-stranded RNA of Ibaraki Virus. Virology 76: 670-674.

20. Tanaka, S. and Roy, P. 1994. Identification of domains in bluetongue virus VP3 molecules essential for the assembly of virus cores. J. Virol. 68: 2795-2802.

21. Thompson, J.D., Higgins, D.G. and Gibson, T.J. 1994. CLUSTAL W: improving the sensitivity of progressive multiple sequence alignment through sequence weighting, position-specific gap penalties and weight matrix choice. Nucleic Acids Res. 22: 4673-4680.

22. Verwoerd, D.W., Els, H.J., De Villers, E.M. and Huismans, H. 1972. Structure of the bluetongue virus capsid. J. Virol. 10: 783-794.

23. Williams, C.F., Inoue, T., Lucus, A.-M., Zanotto, PMA and Roy, P. 1998. The complete sequence of four major structural proteins of African horse sickness virus serotype 6: evolutionary relationships within and between the Orbiviruses. Virus Res. 53: 53-73.

24. Wilson, W.C., Ma, H.-C., Venter, E.H., van Djik, A.A., Seal, B.S. and Mecham, J.O. 2000. Phylogenetic relationships of bluetongue viruses based on gene S7. Virus Res. 67: 141-151. 